\title{
Commentary: How long until a new heart is a "normal" heart in transplanted single-ventricle patients?
}

\author{
Nathanya Baez Hernandez, MD, ${ }^{a}$ and Ryan R. Davies, MD $^{\mathrm{b}}$
}

\footnotetext{
From the Departments of ${ }^{\mathrm{a}}$ Pediatrics and ${ }^{\mathrm{b}}$ Cardiovascular and Thoracic Surgery, UT Southwestern Medical Center and Children's Health, Dallas, Tex.

Disclosures: Authors have nothing to disclose with regard to commercial support

Received for publication Oct 3, 2019; revisions received Oct 3, 2019; accepted for publication Oct 3, 2019 available ahead of print Nov 8, 2019.

Address for reprints: Ryan R. Davies, MD, 1935 Medical District Dr, MC B3.410, Dallas, TX 75235 (E-mail: ryan.davies@utsouthwestern.edu).

J Thorac Cardiovasc Surg 2020;159:1997-8

0022-5223/\$36.00

Copyright (C) 2019 Published by Elsevier Inc. on behalf of The American Association for Thoracic Surgery https://doi.org/10.1016/j.jtcvs.2019.10.004
}

There are few existing data on expectations for hemodynamics changes following transplantation in children with failed single-ventricle (SV) palliation. Diastolic dysfunction manifested by elevated right atrial and wedge pressure (pulmonary capillary wedge pressure, or PCWP) is a known and frequent phenomenon observed during the early posttransplant period in patients. ${ }^{1}$ Filling pressures improve over time, and most patients are asymptomatic with normal systolic function even before resolution of diastolic dysfunction. Whether normalization of posttransplant hemodynamics occurs similarly independent of pretransplant diagnosis is uncertain. The anatomic substrate and abnormal pretransplant physiology of patients with a failed SV place them at particular risk for intraoperative and perioperative posttransplant complications and might contribute to their greater posttransplant mortality. ${ }^{2}$ Thus, understanding how preoperative diagnosis interacts with normalization of postoperative hemodynamics has the potential to provide important insights into dynamic changes in both allograft and patient physiology following transplantation. Furthermore, the timing of normalization of hemodynamics has important implications in understanding what should constitute "normal" posttransplant hemodynamics.

In this issue of the Journal, Stephens and colleagues ${ }^{3}$ provide an initial evaluation of how cardiomyopathy and SV patients' hemodynamics change over time. The authors found that, compared with patients with cardiomyopathy, those with failed SV palliation had delayed normalization of hemodynamics following transplantation. This is not surprising but also previously undocumented. Multiple factors inherent to this population, including pretransplant pulmonary architecture, the risk of silent pulmonary embolism, noncompliant augmented or stented aortas, underlying renal dysfunction, and a more complex intraoperative and perioperative transplant course, all likely contribute to delayed hemodynamics normalization of in this subset of patients.

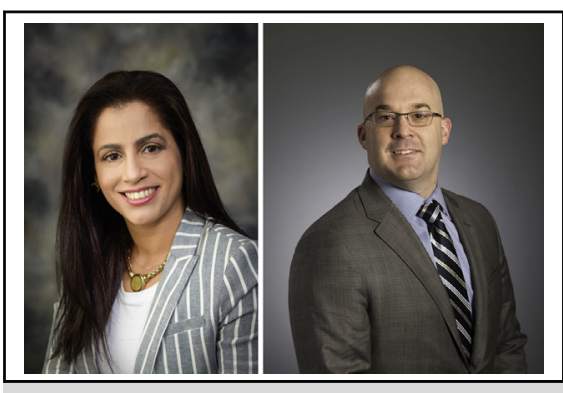

Nathanya Baez Hernandez, MD, and Ryan R. Davies, MD

\section{Central Message}

Delayed normalization of hemodynamics is common following transplantation for failed single-ventricle palliation, but the underlying mechanisms and the impact on graft function and long-term outcomes are uncertain.

See Article page 1986.
Of the parameters measured by Stephens and colleagues (PCWP, pulmonary vascular resistance, and cardiac index), the PCWP had the longest period to normalization, suggesting a combination of diastolic dysfunction and potential volume loading as the result of collaterals. Other potential contributors to elevated PCWP in this complex population include the interaction between renal dysfunction and diastolic cardiac dysfunction (potentially exacerbated in these patients by longer cardiopulmonary bypass times and ischemic time), ${ }^{4}$ as well as abnormal pulmonary vascular resistance. Although acknowledged by the authors, it is important to reinforce that PCWP may not accurately reflect the true left ventricular end-diastolic pressure in patients with pretransplant congenital heart disease and a high risk for associated pulmonary vascular disease. Further details of both right heart and pulmonary vascular hemodynamic data would be important in fully understanding the posttransplant course in these patients, in whom the frequent need for pulmonary artery reconstruction and the potential for residual gradients may impact right graft function.

The authors have highlighted the delayed normalization of the PCWP in failed SV patients posttransplant but have also shown that this delay does not appear to affect shortterm survival. Therefore, the study's principle utility may be in ameliorating family and provider anxiety and minimizing unnecessary invasive and noninvasive procedures. 
Whether this delayed normalization has an impact on midto long-term graft function and survival remains unknown. Studies in adults suggest increased late mortality when either left or right diastolic dysfunction persists beyond 6 months posttransplant, but whether these findings apply to children, especially those with failed SV palliation, is less certain. ${ }^{5}$ Further studies assessing long-term transplant survival in this population would bring a new understanding to the field of pediatric transplantation. Future investigations should seek both to understand the etiology of elevated PCWP (collaterals, renal dysfunction, or intrinsic myocardial dysfunction) and to identify how abnormal hemodynamics influence long-term outcomes.

\section{References}

1. Lunze FI, Colan SD, Gauvreau K, Chen MH, Perez-Atayde AR, Blume ED, et al. Cardiac allograft function during the first year after transplantation in rejection free children and young adults. Circ Cardiovasc Imaging. 2012;5:756-64.

2. Simpson KE, Pruitt E, Kirklin JK, Naftel DC, Singh RK, Edens RE, et al. Fontan patient survival after pediatric heart transplantation has improved in the current era. Ann Thorac Surg. 2017;103:1315-20.

3. Stephens EH, Tannous P, Monge MC, Eltayeb O, Devlin PJ, Backer CL, et al. Normalization of hemodynamics is delayed in single ventricle patients after pediatric heart transplantation. J Thorac Cardiovasc Surg. 2020;159: 1986-96.

4. Davies RR, Sorabella RA, Yang J, Mosca RS, Chen JM, Quaegebeur JM. Outcomes after transplantation for "failed" Fontan: a single-institution experience. J Thorac Cardiovasc Surg. 2012;143:1183-92.

5. Tallaj JA, Kirklin JK, Brown RN, Rayburn BK, Bourge RC, Benza RL, et al. Postheart transplant diastolic dysfunction is a risk factor for mortality. J Am Coll Cardiol. 2007;50:1064-9. 